\title{
Геосистемный подход в географических исследованиях
}

\author{
БАКЛАНОВ П.Я. \\ Федеральное государственное бюджетное учреждение науки \\ Тихоокеанский институт географии ДВО РАН, Владивосток \\ pbaklanov@tigdvo.r
}

\begin{abstract}
Аннотация. Выделяется период становления геосистемного подхода в географических исследованиях. Наиболее полным объектом, в котором отражаются реальные пространственные взаимосвязи и сопряжения различных природных, природно-ресурсных, социальных, инфраструктурных и техногенных компонентов, является интегральная геосистема, выделенная в пределах определенной компактной территории. Пространственное развитие - как качественно-количественные приращения в пространственных структурах - также более полно может охватываться в интегральных геосистемах. Предлагается выделение нескольких уровней пространственного анализа, в том числе локальный уровень отдельных поселений. Интегральные геосистемы и их сочетания должны стать основным объектом разработки региональных программ пространственного развития и территориального управления. Эффективным инструментом управления должны стать геоинформационные, цифровые технологии, большие базы данных, суперкомпьютеры.

Ключевые слова: геосистема, географические исследования, структура, компоненты, связи, территориальная, пространственная, динамика.
\end{abstract}

\section{The geosystem approach in geographical researches}

\author{
BAKLANOV P.Ya. \\ Pacific Geographical Institute, FEB RAS, Vladivostok
}

\begin{abstract}
The period of formation of the geosystem approach in geographical researches is singled out. The fullest object in which real spatial interrelations and interfaces of various natural, natural-resource, social, infrastructural and technogenic components are reflected is the integrated geosystem allocated within certain compact territory. Spatial development also can be covered in integrated geosystems fuller as qualitative-quantitative accretion in spatial structures.

Allocation of several levels of the spatial analysis, including the local one and the level of separate settlements is offered. Integrated geosystems and their combinations should become the basic object of working out of the regional programs of spatial development and territorial governance. Geoinformation, digital technologies, big databases, and supercomputers should become the effective tool of governance.

Keywords: geosystem, geographical researches, structure, components, communications, territorial, spatial, dynamics.
\end{abstract}

\section{Введение}

Впервые системный подход в географических исследованиях в Советском Союзе (России) начал использоваться в конце 60-начале 70-х годов XX столетия. Изучаемый объект в рамках системного подхода должен был рассматриваться либо как 
открытая система, если объект сложный, или как часть системы, если объект простой, однородный. В этом объекте, прежде всего в комплексном, необходимо было выделить внутреннюю структуру, строение, связи, а также внешние связи. В качестве объекта рассматривались как природные образования (растительный покров в пределах определенной территории, почвы, ландшафты, природно-территориальные комплексы), так и социально-экономические (сочетания производственных предприятий, отраслевые сочетания, территориально-производственные сочетания, комплексы, группы населения, поселения и их сочетания). Выделялись и природно-технические системы, например водохранилища с гидротехническими сооружениями, карьеры для открытой добычи угля, стройматериалов и др.

В 1970-е - начале 80-х годов оформилось учение о географических системах (геосистемах). Наибольший вклад в его разработку внесли В.Б. Сочава, В.С. Преображенский, А.Д. Арманд, Ю.Г. Пузаченко, К.Н. Дьяконов, Ю.Г. Симонов, Ю.Г. Саушкин, В.А. Снытко, Э.Г. Коломыц, В.С. Сысуев, А.Ю. Ретеюм, Ю.М. Семенов, Л.М. Корытный и др. [1-12 и др.]. Прежде всего было разработано представление о природных геосистемах как сочетании различных природных компонентов, тесно взаимосвязанных между собой в пределах определенной, достаточно компактной территории. Геосистема рассматривалась как целостное образование, изменяющееся во времени, но сохраняющее свою основу, свой некоторый инвариант. Если в природную геосистему включается человек с его техническими средствами, то геосистема становится интегральной $[9,10,13$ и др.]. В освоенных районах многие геосистемы по существу являются интегральными.

\section{Основные направления геосистемного подхода}

Следует подчеркнуть, что разработка учения о геосистемах стала вполне закономерным итогом развития географических исследований. Во-первых, в качестве наиболее полного объекта, прежде всего на методологическом уровне, рассматривались пространственные образования, включающие компоненты природы, населения и хозяйства. А во-вторых, в реальной действительности природные образования в своей пространственной (территориальной) форме существуют в виде целостных сочетаний тесно взаимосвязанных компонентов: горные породы, почвы, растительность, животные, водные, воздушные. Изменяется один из этих компонентов - изменяются другие, отсутствует один из них - существенно изменяются все другие, либо они просто не могут существовать. В этом состоит фундаментальное доказательство объективности существования целостных природных систем в виде геосистем.

В пространственных (территориальных) образованиях, включающих компоненты населения и хозяйства, также наиболее целостными реально существующими являются сочетания тесно взаимосвязанных социальных (группы населения и формы их жизнедеятельности) и экономических (виды деятельности, хозяйственные предприятия, компании, объекты и организации инфраструктуры и т.п.) образований. Практически все эти компоненты начиная со стадий формирования и в последующих процессах функционирования и развития тесно связаны с природными и природно-ресурсными компонентами. Следует отметить, что компоненты природных ресурсов, будучи изначально природными образованиями, при освоении включаются в хозяйственные, экономические структуры и тем самым выступают как связующие звенья между природными геосистемами и социальноэкономическими, образуя интегральные.

Таким образом, наиболее полным географическим объектом, в котором заключены реально существующие взаимосвязи и сопряжения (пространственные контакты, соседство) различных природных, природно-ресурсных, социальных и экономических компонентов, является интегральная геосистема, объективно существующая в пределах определенной, достаточно компактной территории. 
При переходе к анализу пространственных систем на уровне больших территорий (более мелкомасштабные уровни) многие характеристики и связи обобщаются, а некоторые - опускаются. Поэтому наиболее полными и содержательными остаются геосистемы в пределах относительно небольших, компактных территорий. Такие интегральные геосистемы должны выделяться и анализироваться при разработке комплексных региональных программ долгосрочного развития.

В 1990-е годы начало развиваться представление об устойчивом развитии - как развитии отдельных стран и их регионов с сохранением для будущих поколений достаточного природно-ресурсного потенциала и высоких качеств окружающей среды $[2,14-16]$. Для достижения таких целей необходимым и достаточным условием является охват целостных интегральных геосистем и их сочетаний в пределах страны или региона - как для программных оценок и расчетов, так и для последующего мониторинга.

В последнее время большое внимание начинают уделять пространственному развитию страны, ее регионов $[17,18]$. Пространственное развитие - это определенные количественно-качественные приращения, происходящие в пространственных структурах на разных уровнях: в макро-, мезо- и микроструктурах. Как показывают наши исследования, в наиболее полном, не обобщенном виде пространственное развитие закладывается и реализуется на низших территориальных уровнях - в пространственных структурах интегральных геосистем $[17,19,20]$. Именно на этом уровне существуют, изменяются и развиваются сочетания тесно взаимосвязанных природных компонентов, природно-ресурсных, групп населения, инфраструктурных объектов, технических сооружений, предприятий и поселений в целом, с их собственными пространствами, взаимосвязями, сопряжениями и взаимодействиями. Только в структурах подобных геосистем наиболее полно может оцениваться пространственное развитие, включая передачу изменений от одного компонента другому.

В целом же анализ пространственного развития крупных стран и регионов необходимо проводить на ряде масштабных уровней (см. табл.).

Следует подчеркнуть, что выделение сочетаний отдельных однородных компонентов, природных (растительности, почв, рельефа и т.п.) или социально-экономических (группы населения, отдельных отраслей хозяйства и видов деятельности и т.п.) в качестве объекта географических исследований, является упрощением реальной действительности, значительным абстрагированием. Подобные исследования пока что наиболее распространены, они важны и необходимы для углубленного изучения отдельных компонентов, их размещения, изменений свойств и характеристик. При этом возможны два подхода. В рамках первого изучаются характеристики отдельных компонентов без их взаимосвязи с другими. В рамках второго - геосистемного - необходимо изучение места, функций и взаимосвязей данного компонента с другими в соответствующей геосистеме. В этом случае фактически объектом исследования выступает геосистема в целом.

Предварительными стадиями являются и изучение отдельных компонентов, и выделение соответствующих им природных и интегральных геосистем. Для этих целей важны такие методы, как географическое зонирование и районирование [2, 8, 14, 15 и др.] Выделение природных и интегральных геосистем - это выделение сложных, но реально существующих целостных образований с минимальными упрощениями и абстрагированием и с наиболее полным охватом реальных свойств, межкомпонентных связей, характеристик, в том числе пространственных.

Например, нами разрабатывается подход к выделению территориальных социальноэкономических систем (ТСЭС) в качестве объекта анализа, планирования и управления [17]. Каждое поселение можно рассматривать как своеобразную «точку отсчета структуры», как центральный элемент системы. Именно в поселении заключены реально существующие взаимосвязи между социальными компонентами и экономическими, а также их взаимодействия с природными и природно-ресурсными компонентами. 
Уровни анализа пространственного развития, характеристики, цели

Table. Levels of the spatial development analysis, characteristics, goals

\begin{tabular}{|c|c|c|}
\hline $\begin{array}{c}\text { Уровни анализа } \\
\text { пространственного } \\
\text { развития }\end{array}$ & Оцениваемые свойства, характеристики & Цели анализа \\
\hline $\begin{array}{l}\text { 1. Макрорегионы } \\
\text { (в т.ч. Дальневосточный) }\end{array}$ & $\begin{array}{l}\text { - Численность населения и общая его } \\
\text { динамика; } \\
\text { - Валовой региональный продукт и его } \\
\text { изменения; } \\
\text { - Промышленный, сельскохозяйственный } \\
\text { продукт, инвестиции; } \\
\text { - Производство товаров и услуг в } \\
\text { специализированных видах деятельности; } \\
\text { - Межрегиональные связи; } \\
\text { - Экспортно-импортные связи. }\end{array}$ & $\begin{array}{l}\text { Общий потенциал макрорегиона, } \\
\text { его место в стране в сравнении с } \\
\text { другими макрорегионами. } \\
\text { Участие в межрегиональных и } \\
\text { экспортно-импортных связях. }\end{array}$ \\
\hline $\begin{array}{l}\text { 2. Субъекты РФ (края, } \\
\text { области, республики) }\end{array}$ & $\begin{array}{l}\text { - Основные характеристики населения и } \\
\text { динамики, в т.ч. половозрастная структура; } \\
\text { - Производство товаров и услуг, в т.ч. в } \\
\text { специализированных, приоритетных видах } \\
\text { деятельности; } \\
\text { - Инвестиции, финансы; } \\
\text { - Природно-ресурсный потенциал и его } \\
\text { использование; } \\
\text { - Характеристики энергетики, транспорта, } \\
\text { внутренних и внешних рынков. }\end{array}$ & $\begin{array}{l}\text { Основные (приоритетные) виды } \\
\text { деятельности, их стабильность. } \\
\text { Достаточность инвестиций. } \\
\text { Природно-ресурсный потенциал } \\
\text { и его значение. } \\
\text { Обеспеченность приоритетов: } \\
\text { - трудовыми и природными } \\
\text { ресурсами; } \\
\text { - финансированием, } \\
\text { инфраструктурой. }\end{array}$ \\
\hline 3. Дробные районы & $\begin{array}{l}\text { - Основные виды деятельности; } \\
\text { - Основные структуры природопользования. }\end{array}$ & $\begin{array}{l}\text { Наличие эколого-экономических } \\
\text { проблем и ограничений. }\end{array}$ \\
\hline $\begin{array}{l}\text { 4. Муниципальные } \\
\text { образования, отдельные } \\
\text { поселения. }\end{array}$ & $\begin{array}{l}\text { - Функциональная структура, в т.ч. } \\
\text { основные виды деятельности; } \\
\text { - Население, его потенциал; } \\
\text { - Ввоз-вывоз продукции; } \\
\text { - Инфраструктура; } \\
\text { - Структуры природопользования, в т.ч. в } \\
\text { пригородном поясе. }\end{array}$ & $\begin{array}{l}\text { Устойчивость, эффективность } \\
\text { поселения. Роль внутренних } \\
\text { факторов его развития. Наличие } \\
\text { резервов территории, в } \\
\text { инфраструктуре, в населении. }\end{array}$ \\
\hline $\begin{array}{l}\text { 5. Территориальные } \\
\text { социально-экономические } \\
\text { системы (ТСЭС) }\end{array}$ & $\begin{array}{l}\text { - В поселениях - основные виды } \\
\text { деятельности, приоритетные; } \\
\text { - Обеспеченность собственным населением; } \\
\text { - Характеристика транспортных звеньев; } \\
\text { - Характеристика пространственных } \\
\text { звеньев природопользования. }\end{array}$ & $\begin{array}{l}\text { Связанность поселений, их } \\
\text { взаимозависимость в процессе } \\
\text { развития. Связанность } \\
\text { поселений со структурами } \\
\text { природопользования, их } \\
\text { взаимозависимость. }\end{array}$ \\
\hline
\end{tabular}

Если выделить все другие поселения, непосредственно связанные с центральным транспортными путями, то получим структуру ТСЭС I порядка. При наличии значительных связей и взаимозависимости в эту систему могут включаться отдельные звенья II и других порядков - поселения, связанные опосредованно с центральным. Кроме того, в ТСЭС должны включаться все звенья природопользования и резервные территории, непосредственно связанные со структурными звеньями I порядка: структуры землепользования, лесопользования, водопользования, недропользования и др. Поселения в ТСЭС включаются с поясом их территориально-акваториального окружения. В самих поселениях выделяются условно-переменные (основные, приоритетные) и условно-постоянные виды деятельности, группы населения, инфраструктура, социальная сфера и т.д. Выделенная таким образом ТСЭС с корректировкой ландшафтных границ по своему содержанию является интегральной геосистемой. На модельном, расчетном уровне в эту систему можно «включать» (или - «исключать») новые инвестиционные проекты - в виде пространственных линейно-узловых систем и оценивать всю цепочку пространственных структурных трансформаций, связанных вариантами реализаций данного инвестиционного проекта. 


\section{Заключение}

Таким образом, интегральные географические системы следует рассматривать как наиболее полный объект планирования и управления устойчивым пространственным развитием. Для этих целей эффективным инструментом должны стать современные геоинформационные системы и технологии, в том числе цифровые технологии на основе больших баз данных. В этой связи геосистемный подход в географических исследованиях должен получить «второе дыхание». В подобном виде он не только приближает исследования к отражению наиболее глубинных, фундаментальных свойств реально существующих геосистем, но и имеет большую практическую направленность. Например, для разработки программ устойчивого развития регионов и территорий последние необходимо выделять и анализировать в рамках геосистемного подхода.

Результаты исследований, представленные в статье получены в рамках государственного задания Минобрнауки РФ («Географические и геополитические факторы в инериионности, динамике и развитии разно ранговых территориальных структур хозяйства и расселения населения Тихоокеанской России», № АAАA-A16-116110810013-5. Раздел 1), а также при финансовой поддержке РФФИ в рамках научного проекта № 18-05-80006.

\section{Литература}

1. Арманд А.Д. Самоорганизация и саморегулирование географических систем. М.: Наука, 1988. 264 с.

2. Географические исследования Сибири. Т. 1. Структура и динамика геосистем / Ю.М. Семенов, А.В. Белов, Е.Г. Суворов и др. Новосибирск: Гео, 2007. 413 с.

3. Дьяконов К.Н. Информационный подход к анализу организации геосистем топологического уровня // Вопросы географии. Сб. 127. Моделирование геосистем. М.: Мысль, 1986. С. 111.

4. Коломыц Э.Г. Ландшафтные исследования в переходных зонах. М.: Наука, 1987. 117 с.

5. Корытный Л.М. Бассейновая концепция в природопользовании. Иркутск: ИГ СО РАН, 2001. 163 с.

6. Преображенский В.С. Организация, организованность ландшафтов. Препр. М.: Ин-т географии АН CCCP, 1986. $20 \mathrm{c}$.

7. Пузаченко Ю.Г. Инвариантность геосистем и их компонентов // Устойчивость геосистем. М.: Наука, 1983. C. $32-41$.

8. Ретеюм А.Ю. Физико-географическое районирование и выделение геосистем // Вопр. географии. Сб. 98. М.: Мысль, 1975. С. 5-27.

9. Саушкин Ю.Г. Экономическая география: история, теория, методы, практика. М.: Мысль, 1973. 559 с.

10. Симонов Ю.Г. Основные свойства объектов географического прогнозирования и способы их формального описания // Проблемы регионального географического прогноза. М.: Наука, 1982. С. 112-193.

11. Снытко В.А. Геохимические исследования метаболизма в геосистемах. Новосибирск: Наука, 1978. 149 с.

12. Сысуев В.В. Основные концепции физико-математической теории геосистем // Вопр. географии. Сб. 138: Горизонты ландшафтоведения. М.: Кодекс, 2014. С. 65-100.

13. Сочава В.Б. Введение в учение о геосистемах. Новосибирск: Наука, 1978. 320 с.

14. Геосистемы Дальнего Востока на рубеже XX-XXI веков. Т. 1 / отв. ред. С.С. Ганзей. Владивосток: Дальнаука, 2008. $428 \mathrm{c}$.

15. Геосистемы Дальнего Востока на рубеже XX-XXI веков. Т. 2 / отв. ред. П.Я. Бакланов, В.П. Каракин. Владивосток: Дальнаука, 2010. 560 с.

16. Россия и ее регионы: интегральный потенциал, риски, пути перехода к устойчивому развитию. М.: Т-во научных изданий КМК, 2012. 490 с.

17. Бакланов П.Я. Территориальные социально-экономические системы в региональном развитии // Изв. РАН. Серия геогр. 2017. № 4. С. 7-16.

18. Проблемы регионального развития России // Вопр. географии. № 141. М.: Кодекс, 2016. 640 с.

19. Бакланов П.Я. Подходы и основные принципы структуризации географического пространства // Изв. РАН. Серия геогр. 2013. № 5. С. 7-18

20. Бакланов П.Я. Территориальная организация и пространственное развитие: соотношение понятий и процессов // Геосистемы восточных районов России: особенности их структур и пространственного развития. Владивосток: ТИГ ДВО РАН, 2019. С. 10-16. 


\section{References}

1. Armand, A.D. Self-organization and self-regulation of the geographical systems. Moscow: Nauka, 1988. 264 p. (In Russian).

2. Geographical investigations of Siberia. V.1. Structure and dynamics of geosystems / Yu.M. Semenov, A.V. Belov, E.G. Suvorov etc. Novosibirsk: Geo, 2007. 413 p. (In Russian)

3. Dyakonov, K.N. Information approach to analyzing the organization of the geosystems of topological level. Problems of geography. Collected papers 127. Simulation of geosystems. Moscow: Mysl, 1986. P. 111. (In Russian).

4. Kolomyts, E.G. Landscape studies in the transition zones. Moscow: Nauka, 1987. 117 p. (In Russian).

5. Korytny, L.M. Basin conception in the nature management. Irkutsk, Institute of Geography, SB of RAS. 2001. 163 p. (In Russian).

6. Preobrazhensky, V.S. Organization, organized nature of landscapes (preprint). Moscow: Institute of Geography, USSR Academy of Sciences, 1986. 20 p.

7. Puzachenko Yu.G. Invariance of geosystems and their components, Stability of geosystems. Moscow: Nauka, 1983. P. 32-41. (In Russian).

8. Reteyum, A.Yu. Physical-geographical regionalization and identification of geosystems. Problems of geography. Coll. papers 98. Moscow: Mysl, 1975. P. 5-27. (In Russian).

9. Saushkin, Yu.G. Economic geography: history, theory, methods, practice. Moscow: Mysl, 1973. 559 p. (In Russian)

10. Simonov, Yu.G. Basic properties of the geographical prediction objects and methods of their formal description / Problems of the regional geographical prediction. Moscow: Nauka, 1982. P. 112-193. (In Russian).

11. Snytko, V.A. Geochemical studies of metabolism in the geosystems. Novosibirsk: Nauka, 1978. 149 p. (In Russian).

12. Sysuyev V.V. Basic concepts of the physic-mathematical theory of geosystems // Problems of geography. Coll. papers 138: Horizons of the landscape science.Moscow: Kodeks. 2014 P. 65-100. (In Russian).

13. Sochava, V.B. Introduction to the theory of geosystems. Novosibirsk: Nauka, 1978. 320 p. (In Russian).

14. Geosystems of the Far East on the cusp of the XX and XXI centuries. V.1. / Editor-in-chief: S.S. Ganzei. Vladivostok: Dalnauka, 2008. 428 p. (In Russian).

15. Geosystems of the Far East on the cusp of the XX and XXI centuries. V.2. / Editors-in-chief: P.Ya. Baklanov, V.P. Karakin. Vladivostok: Dalnauka, 2010. 560 p. (In Russian).

16. Russia and its regions: integrated potential, risks, ways of transition to the sustainable development. Moscow: Creation of scientific publications of KMK, 2012. 490 p. (In Russian).

17. Baklanov, P.Ya. Territorial social and economic systems in the regional development. Proceedings of RAS. Ser. geographical. 2017. № 4. P. 7-16. (In Russian).

18. Problems if the regional development of Russia. Problems of geography. No. 141, Moscow: Kodeks, 2016. 640 p. (In Russian).

19. Baklanov P.Ya. Approaches and main principles of the geographical space structuring // Proceedings of RAS. Ser. geographical. 2013. No. 5. P. 7-18. (In Russian).

20. Baklanov P.Ya. Territorial organization and spatial development: ratio of concepts and processes. Geosystems of the eastern areas of Russia: features of their structures and spatial development. Vladivostok: Federal Publicly Funded Institution of Science Pacific Geographical Institute, FEB of RAS, 2019. P. 10-16. (In Russian). 